\title{
EL DESARROLLO DE LAS COMPETENCIAS LITERARIAS, UNA "INVERSIÓN" EDUCATIVA SOCIALMENTE RENTABLE
}

Resumen: En este momento nadie cuestiona la importancia educativa, emocional y hasta social del desarrollo de las competencias creativas. En el caso de las literarias, estas, además, favorecen el mejoramiento de la recepción y la expresión verbal. Por ello, dar cauce didáctico a estas exigencias o conveniencias, como quieran entenderse, resulta fundamental en una educación cada vez más ligada al futuro desempeño profesional, centrado específicamente en habilidades tecnológicas y economicistas. En este sentido, los talleres de escritura son esenciales para el desarrollo personal y resiliente.

Palabras clave: competencia, creatividad, educación emocional, literatura, resiliencia.

\section{THE DEVELOPMENT OF THE LITERARY COMPETENCES, AN EDUCATIVE "INVESTMENT" SOCIALLY PROFITABLE.}

\begin{abstract}
At this point nobody questions the educative, emotional and even social importance of the development of the creative competences. In the case of the literary, this also, favours the improvement of the verbal expression and the reception. That is why, giving didactic opening to these demands or conveniences, as you wish to understand, results fundamental in a kind of education that is every time more linked to the future professional performance, specifically centered in the economical and technological skills. In this sense, the writing workshops are essential for the personal and resilient development.
\end{abstract}

Key words: competence, creativity, emotional education, literature, resilience.

Forma de citar: Reyzábal, V. (2016) "El desarrollo de las competencias literarias, una “inversión” educativa socialmente rentable". Voces de la Educación, 1 (1) pp. 87-98.

Ma Victoria Reyzábal: Directora de investigación del Instituto Superior de Promoción Educativa (Madrid). España

Correo Electrónico: mvreyzabal@gmail.com

Fecha recepción: 16 de enero Fecha aceptación: 3 de febrero 


\section{EL DESARROLLO DE LAS COMPETENCIAS LITERARIAS, UNA "INVERSIÓN" EDUCATIVA SOCIALMENTE RENTABLE}

\section{EI "mal negocio" de lo literario}

Pocos padres felicitarían a sus retoños si estos les comunicaran la intención de dedicarse profesionalmente a la actividad literaria. Tampoco es previsible que dichos progenitores seleccionaran un taller literario como elemento destacado de la formación de sus hijos, a diferencia de lo que sucede con el aprendizaje de idiomas, informática, deportes... Es más, ni siquiera los profesionales de la educación o los responsables políticos del diseño e implementación de esta son demasiado claros ni categóricos cuando valoran en los currículos la repercusión del mejoramiento de las competencias literarias sobre la evolución cognitiva del alumnado acerca de las que versan sus sesudas reflexiones y planificaciones. No, existen indicios suficientes y preocupantes para concluir que los contenidos relacionados con la comprensión y la expresión literarias no constituyen una prioridad en los diseños curriculares ni en la educación no formal de los ciudadanos (principalmente niños y jóvenes, pero también de los adultos) en nuestras sociedades occidentales y capitalistas. Prima el imperio de lo tecnológico, lo científico o lo económico como garantía aparentemente infalible de futuros éxitos profesionales y del logro del consiguiente prestigio social. ¡Ah, el éxito y la fama rápida y global!, ese anhelo cada vez más pujante en nuestras generaciones jóvenes y que apenas requiere ya méritos especiales, sino lograr -sin importar el precio o los medios- la máxima visibilidad en los medios de comunicación (tradicionales o cibernéticos) estimulada por motivos mayoritariamente insustanciales pero que garantizan al menos un instante de gloria (de "celebridad") y de proyección social aunque esta sea fugaz e insulsa.

No pueden "correr buenos tiempos para la lírica"l cuando las referencias para la sociedad son personajes como Belén Esteban, Victoria Beckham, Jorge Javier Vázquez o los omnipresentes nuevos divos de la cocina, mientras se desconoce y ningunea por completo la aportación científica de la bioquímica Margarita Salas, la bióloga molecular María Blasco, el neurocientífico Rafael Yuste... o, con más inquina, la de escritores y pensadores a menos de que hayan sido aupados a las listas de los libros más vendidos (en la categoría de novelas, obras de autoayuda u otros inventos contemporáneos) o seleccionados confesos por políticos o figurones.

Semejante ansia de hedonismo y de logros fáciles y pasajeros genera un malestar personal y social tan profundo que convierte en prioritaria la reivindicación del poder formador, emocionalmente equilibrador e incluso terapéutico de la expresión artística ${ }^{2}$, en particular, de la literaria. No pocos intelectuales han incidido en el poder de las palabras y de la combinación de estas en eslóganes, poemas, cuentos, novelas, canciones... para lograr efectos poderosos, a veces desgraciadamente, incluso, bélicos. Así lo hacía Sartre al señalar que "Escribir [...] tiene reverberaciones sobre todas las

\footnotetext{
${ }^{1}$ En alusión al poema "Malos tiempos para la lírica" de Bertolt Brecht, expresión retomada con otras connotaciones por el grupo musical vigués Golpes Bajos en plena "movida" de los años 80.

${ }^{2}$ Fiske, E. (2002). Champions of change. The impact of the arts on learning. Washington: The John and Catherine T. McArthur Foundation.

Voces de la Educación

Volumen 1 Año 1

ISSN en trámite

Enero - Junio 2016
} 
manifestaciones de la vida"3, o más recientemente el mexicano Jorge Volpi ${ }^{4}$ y, magistralmente, el peruano Mario Vargas Llosa en su discurso de aceptación del Premio Nobel de Literatura: “[...] la ficción es más que un entretenimiento, más que un ejercicio intelectual que aguza la sensibilidad y despierta el espíritu crítico. Es una necesidad imprescindible para que la civilización siga existiendo, renovándose y conservando lo mejor de lo humano. Para que no retrocedamos a la barbarie de la incomunicación y la vida no se reduzca al pragmatismo de los especialistas que ven las cosas en profundidad pero ignoran lo que las rodea, las precede y continúa [...] un mundo sin literatura sería un mundo sin deseos ni ideales ni desacatos, un mundo de autómatas privados de lo que hace que el ser humano sea de veras humano: la capacidad de salir de sí mismo y mudarse en otro, en otros, modelados con la arcilla de nuestros sueños. De la caverna al rascacielos, del garrote a las armas de destrucción masiva, de la vida tautológica de la tribu a la era de la globalización, las ficciones de la literatura han multiplicado las experiencias humanas, impidiendo que hombres y mujeres sucumbamos al letargo, al ensimismamiento, a la resignación. Nada ha sembrado tanto la inquietud, removido tanto la imaginación y los deseos, como esa vida de mentiras que añadimos a la que tenemos gracias a la literatura para protagonizar las grandes aventuras, las grandes pasiones, que la vida verdadera nunca nos dará. Las mentiras de la literatura se vuelven verdades a través de nosotros, los lectores transformados, contaminados de anhelos y, por culpa de la ficción, en permanente entredicho con la mediocre realidad [...] la literatura introduce en nuestros espíritus la inconformidad y la rebeldía, que están detrás de todas las hazañas que han contribuido a disminuir la violencia en las relaciones humanas", nos ha enseñado a amar, a soñar y a aceptar a los otros.

\section{Aportación de las Neurociencias al conocimiento de los efectos de la expresión literaria}

Hablar de estas cuestiones no implica únicamente realizar reflexiones abstractas o desarrollar intuiciones más o menos bellamente expresadas. Hoy, cuando parece que necesitamos objetivar cualquier afirmación o idea con pruebas "científicas" y tangibles, la neurociencia respalda con argumentos de contundencia creciente lo que ya muchos decíamos o habíamos constatado en la práctica profesional y en nuestra experiencia vital. En primer lugar, se ha podido observar en registros del funcionamiento cerebral que la recepción de una historia (bien escrita, bien hablada) activa los mismos centros que la vivencia directa de la misma, es decir, que la recepción de relatos puede ampliar prácticamente sin límites nuestro registro de experiencias. Lo resume bien Ann Murphy Paul cuando señala que "El cerebro, al parecer, no distingue entre leer sobre una experiencia y toparse con ella en la vida real; en cada caso, se estimulan las mismas regiones neurológicas" 5 .

Nuestro sistema nervioso central se muestra extremadamente sensible a la carga afectiva y a la sonoridad de las palabras que percibe. Así, en el ámbito del neuromarketing, investigadores como Paul Zak han comprobado experimentalmente que la escucha de

\footnotetext{
${ }^{3}$ Sartre, J. P. (1945). Prólogo del $\mathrm{n}^{\circ} 1$ de Les temps moderns.

4 "Leer una novela o un cuento no es una actividad inocua: desde el momento en que nuestras neuronas nos hacen reconocernos en los personajes de ficción -y apoderarnos así de sus conflictos, sus problemas, sus decisiones, su felicidad o su desgracia-, comenzamos a ser otros. Conforme más contagiosas -más aptassean las ideas que contiene una narración, sus secuelas quedarán más tiempo incrustadas en nuestra mente, como las secuelas de una enfermedad viral o de una fiebre terciaria. La única cura es, por supuesto, el olvido. Y la lectura de otras novelas" (Leer la mente. Madrid, Alfaguara, 2011). La ficción narrativa resulta tan preciosa para los seres humanos que, según Jonathan Gottschall (2012), construir historias constituye una tarea continua, imparable, en las personas. De hecho, narrar, inventarnos continuamente relatos, incluso sobre nosotros mismos, es una labor que nos transforma en humanos plenos y conscientes de nuestra identidad, algo que plantea desde otra perspectiva la psicoterapia narrativa.
}

${ }^{5}$ Your Brain on Fiction. The New York Times, 18 de marzo de 2012.

Voces de la Educación

ISSN en trámite

Volumen 1 Año 1

Enero - Junio 2016 
determinadas narraciones con elevado contenido emocional induce respuestas neuroendocrinas (en concreto secreción de oxitocina, hormona con reconocidos efectos afrodisíacos) que las historias afectivamente "neutras" no provocan. Quizá esa reacción fisiológica del cerebro, en la que intervienen las "neuronas espejo" explique, por ejemplo, cómo la simple lectura o visión de historias pornográficas pueden sustituir la vivencia directa del acto sexual ${ }^{6}$ o cómo personas que viven aisladas o muy limitadas por diversas circunstancias pueden vivir a través de los libros sin que esto sea metafórico (de hecho, existe constancia de que muchos presos han resistido las duras condiciones de su encerramiento gracias únicamente a la "ventana al exterior" que les abría la lectura).

Los estudios realizados por diversos expertos confirman que la fuerza, casi mágica, que poseen las palabras tiene que ver fundamentalmente con su naturaleza sonora y emotiva, rasgos que activan poderosamente determinadas regiones del cerebro. Por ejemplo, el equipo de Nicola Molinaro ${ }^{7}$ ha puesto de manifiesto cómo determinadas imágenes retóricas (en concreto el oxímoron) estimulan intensas descargas eléctricas en las células nerviosas de ciertas regiones del lóbulo frontal, al contrario de lo que sucede con expresiones carentes de esa riqueza fonética o estética, que dejan "impasible" nuestro encéfalo.

El fenómeno sensorial que implica ante todo el lenguaje, mediado por la vías acústicas o visuales, conduce, cada vez que se capta un significante, a la puesta en marcha de reacciones extremadamente veloces, incluso más que la propia emisión/lectura de la palabra. De tal forma, los psicolingüistas han comprobado ya mediante técnicas neurofuncionales que la mente humana analiza los fonemas en sí mismos antes de tener acceso al vocablo completo. El proceso, aunque variable según cada término, siempre se produce en milisegundos, con anterioridad a la recepción y, sobre todo al análisis del significado. Esto sucede también incluso cuando se lee, es decir, cuando la percepción es visual y no sonora.

Por último, y para no sobrecargar las referencias a la hoy todopoderosa neurociencia ${ }^{8}$, quiero referirme a una última investigación conducida por David Comer y Enmanuele Castano ${ }^{9}$, que, usando en este caso diversos tests neuropsicológicos, demuestran que la lectura de textos de ficción ejerce un beneficioso y profundo impacto en el desarrollo de la empatía, es decir, la capacidad de comprender las emociones que experimentan otras personas. Esta investigación resulta destacable en otro aspecto más, ya que sus resultados muestran que los efectos logrados difieren en función de la "calidad" de los textos utilizados: mientras que las obras literarias logran ese impacto sobre la competencia emocional del receptor, no sucede lo mismo con los ensayos y los escritos sin valor estético-literario (entre los que podríamos incluir los llamados super-ventas). Hallazgos similares arrojan los estudios llevados a cabo por el equipo coordinado por Natalie Phillips ${ }^{10}$, profesora de la Universidad Estatal de Michigan, cuyas investigaciones -llevadas a cabo con resonancia magnética funcional asociada a dispositivos de seguimiento ocular- ponen de manifiesto que la lectura de obras con calidad literaria (es decir, con mérito estético reconocido, como las

6 Porn and mirror neurons, Jonah Lehrer, 24 de agosto de 2009, http://scienceblogs.com/cortex/2009/08/24/porn-and-mirror-neurons/

${ }^{7}$ Molinaro N., Carreiras M. y Duñabeitia JA. (2012). Semantic combinatorial processing of non-anomalous expressions. Neuroimage, 59, 3488-3501.

8 El lector que quiera ampliar y profundizar en los actuales conocimientos sobre las cuestiones neurocientíficas vinculadas al fenómeno literario puede consultar el interesante compendio coordinado por P. Armstrong, How Literature Plays with the Brain. The Neuroscience of Reading and Art (2013). Baltimore: Johns Hopkins University Press.

${ }^{9}$ Comer Kidd D., Castano E. (2013). Reading Literary Fiction Improves Theory of Mind. Science, 342, 18 de octubre de 2013, 377-380.

${ }^{10}$ Phillips N. (en prensa). Distraction: Problems of Attention in Eighteenth-Century Literature. Baltimore: Johns Hopkins University Press. 
novelas de Austen) activa potentemente regiones cerebrales relacionadas con la focalización de la atención, la planificación de tareas y otras funciones cognitivas complejas.

\section{De las competencias literarias a la resiliencia personal y grupal}

¿Dónde nos conducen todos estos valiosos hallazgos acerca de la interacción textosujeto receptor (e hipotéticamente también emisor)? En definitiva, no hacen sino confirmar la idea que he defendido en diferentes publicaciones previas, del enorme potencial de los talleres literarios (en su vertiente receptiva y creativa) como vía de transformación y estímulo del crecimiento de los seres humanos, incluso cuando estos han experimentado experiencias traumáticas terribles que han puesto a prueba su capacidad de resistir y proyectarse hacia el futuro (o lo que es lo mismo, de ser resilientes $\left.{ }^{11}\right)^{12}$. La lectura y producción planificada de textos literarios permite, de acuerdo con lo observado por mí en múltiples experiencias, poner en marcha lo que Henderson y Milstein ${ }^{13}$ denominan "rueda de la resiliencia", un sencillo modelo que puede usarse como guía para la transformación de cualquier dinámica pedagógica siguiendo las líneas maestras propuestas por el paradigma de la resiliencia. Los talleres literarios, que pueden ser dirigidos a los grupos más heterogéneos, constituyen espacios de trabajo con la potencialidad de:

1. Enriquecer los vínculos. La actividad literaria constituye en principio una actividad básicamente individual y más bien solitaria. No obstante, el tipo de trabajo que se desarrolla en los talleres de fomento de la competencia literaria prima en todo momento la tarea colectiva por encima del logro aislado de cada miembro, huyendo así de la competitividad. A lo largo de la consolidación del grupo que conlleva cualquier taller se constata de qué forma este asume como propios los avances de cada integrante y cómo los componentes celebran la superación de inhibiciones de los compañeros más reticentes y valoran los primeros pasos de los que tardan más en decidirse a participar o las mejoras logradas por cada integrante en las sucesivas correcciones de una determinada producción. La brillantez de los logros individuales queda relegada a un segundo plano, disfrutándose sobre todo las producciones elaboradas gracias a las aportaciones colectivas. Más aún, la inmersión en las obras propuestas como modelos favorece el establecimiento de una vinculación muy peculiar, calificable atrevidamente de cuántica en la medida que transciende los límites espacio-temporales y permite el tránsito por mundos paralelos. En cierta forma, los aprendices de escritores establecen relaciones de simpatía, identificación o admiración con autores lejanos histórica o geográficamente, pero llamativamente próximos en función de la magia que implica la reactualización de sus textos en el aquí y el ahora. Lógicamente, mucho más inmediata es la conexión que puede establecerse con los compañeros de grupo al compartir cognitiva y emocionalmente lo que han plasmado en el papel.

2. Establecer límites claros y firmes. Los avances conseguidos en el dominio del uso del código verbal se traducen de forma casi inmediata en el establecimiento de límites conductuales precisos, dados los efectos autorreguladores propios de este código expresivo en sus concreciones orales o escritas (y que tan bien conocen los que defienden la Programación Neurolingüística o el cada vez más popular "entrenamiento personal" o "coaching"). Si cabe, el perfeccionamiento del uso del registro literario del lenguaje conlleva matices aún más exigentes de esta autorregulación, pues la superior complejidad de las

\footnotetext{
${ }^{11}$ Reyzábal MV. y Sanz AI. (2014). Resiliencia y acoso escolar. La fuerza de la educación. Madrid: La Muralla.

Reyzábal MV. (2014). Literary Practice as a way to Promote Resilience. Procedia- Social an Behavioral Sciences, 132, 15 de mayo 2014, 121-128.

${ }^{12}$ En ese sentido, quiero recordar experiencias -no publicadas pero sí profundamente incorporadas a mi bagaje personal- cuyos escenarios fueron cárceles u hospitales psiquiátricos.

${ }^{13}$ Henderson N., Milstein, M. (2003). Resiliencia en la escuela. Buenos Aires: Paidós.

Voces de la Educación

ISSN en trámite

Volumen 1 Año 1

Enero - Junio 2016
} 
reglas $\mathrm{u}$ opciones que sustentan esta variante del código verbal exige una profunda implicación del descodificador/productor de discursos literarios en el conocimiento, respeto y valoración de las pautas que regulan la actividad a la que se enfrenta. A la vez y quizá paradójicamente, el código verbal literario -regulado por pautas (fonológicas, sintácticas, semánticas, retóricas, textuales...) precisas- permite, es más, fomenta la ruptura de las mismas siempre que tal "rebelión" frente a lo establecido conlleve la plasmación de logros estéticos y no revele tan solo el desconocimiento del código o la falta de preocupación por la propiedad o la coherencia de estilo, técnica o género del mensaje que se desea transmitir aun a partir de la ruptura de las normas tradicionales.

3. Enseñar habilidades para la vida. La mejora de la competencia literaria consigue avances significativos en el ámbito de todas y cada una de las diez habilidades para la vida planteadas por la $\mathrm{OMS}^{14}$. Como señalan numerosos autores, la implementación de dichas capacidades cognitivo-afectivo-sociales se traduce en el desarrollo equilibrado de una personalidad fuerte y a la vez flexible ante las múltiples exigencias de la existencia (provenientes tanto de conflictos internos como de sucesos externos adversos), que podríamos identificar con lo que se ha denominado un "yo resiliente" (Tabla 1).

Desgrano a continuación en someras pinceladas lo que el desarrollo de las competencias literarias aporta a los diferentes aspectos de esas capacidades para vivir mejor y más plenamente.

\section{A. Habilidades sociales}

- Conocimiento de sí mismo: Para ello, conviene situarse en la posición de plasmar verbalmente con belleza un texto literario, lo que nos obliga a volver la mirada hacia el interior para buscar las claves de nuestra experiencia y nuestra conducta. Cuando creamos una historia, un poema, un drama o un ensayo, bien en primera persona, bien asumiendo la identidad de otras voces, explicitamos lo que somos, haciéndolo más consciente al perfeccionar esa producción o al releerla para nosotros mismos o ante los demás.

- Empatía: Al comentar cualquier obra escrita necesariamente nos forzamos a adentrarnos en las acciones y la subjetividad de los otros, tanto de los personajes que pueblan esa ficción como de la mente que en su momento les dio vida. Semejante proceso resulta aún más complejo y enriquecedor cuando -como autores-, abandonamos la primera persona para adoptar el punto de vista de un tercero o terceros, especialmente si este se distancia mucho de nuestras circunstancias vitales y posiciones intelectuales o existenciales (identidad sexual, procedencia cultural, estatus social, tipo de creencias, etc.).

- Comunicación asertiva: La comprensión y producción de composiciones literarias implica necesariamente perfeccionar la capacidad de transmitir verbalmente con precisión, corrección y pertinencia los pensamientos, opiniones, deseos, fantasías a los muy diversos "otros" con que podemos interaccionar en distintos momentos de nuestra vida. La heterogeneidad de las situaciones comunicativas en las que nos colocan los textos literarios permite implementar la flexibilidad y versatilidad de nuestro discurso, adaptándolo al contexto y a las características de los receptores. Cuando ese esfuerzo se concreta con éxito se garantiza que el intercambio comunicativo tenga lugar con la máxima eficacia y riqueza posible.

- Relaciones interpersonales: Lograr interacciones humanas positivas supone, entre otros eslabones esenciales, el perfeccionamiento de las capacidades

\footnotetext{
${ }^{14}$ World Health Organization (1993). Life Skills Education for Children and Adolescents in Schools. Ginebra: World Health Organization. 
receptivas y expresivas. Los vínculos que establecemos con los otros mejoran en la medida que lo hace la claridad y fluidez de la expresión verbal de nuestras intenciones.

\section{B. Habilidades cognitivas}

- Capacidad para tomar decisiones: La doble vertiente de descodificar y/o producir textos literarios implica desde el primer momento aprender a plantearse interrogantes que a su vez exigen la puesta en práctica de procesos tanto deductivos como inductivos dirigidos a profundizar la tarea iniciada. Aunque inicialmente la preguntas y las sugerencias acerca de cómo resolverlas serán guiadas por un docente o coordinador experto en el tema, el objetivo final será que el propio individuo sea capaz de planificar y concretar el trabajo de comentario de un determinado escrito o la producción autónoma de su propio texto.

- Capacidad para resolver problemas y conflictos: Toda historia o composición lírica implica una plasmación de situaciones vitales (amores, pérdidas afectivas, dilemas existenciales o éticos, lucha con la rutina...) que colocan a su emisor en una encrucijada. La recepción o la creación de textos literarios exige inevitablemente colocarse ante potenciales conflictos vitales y valorar las respuestas que aportan el/los protagonistas de la ficción para, posiblemente, acabar sopesando otras alternativas fruto de la reflexión personal y grupal.

- Pensamiento crítico: La literatura es, ante todo, cuestionamiento que no se conforma con que ningún asunto admita un planteamiento único. En consecuencia, fuerza a un continuo preguntarse por los cómos y los porqués de cada situación y llega a la conclusión de que, casi siempre, es posible otra forma de realidad alternativa. Más aún, busca que esa propuesta superadora de un determinado dilema sea menos injusta o alienante, en definitiva, que resulte humanizadora. Así lo hicieron autores tan diferentes como Cervantes, Shakespeare, Virginia Woolf, Borges, Cortázar, Rulfo, García Lorca, Paz o García Márquez... entre otros muchos, que transmiten al que se anima a crear obras teatrales, novelísticas o poéticas la idea de que no hay que conformarse nunca con lo que se considera incuestionable, que siempre hay que ahondar más allá y buscar algo nuevo y mejor para los individuos y para el conjunto de la Humanidad.

- Pensamiento creativo: No existe una variante más creativa de la expresión que la literaria. El que escribe (y lee) literatura busca la belleza, la originalidad, el discurso no útil sino impactante por su lograda conjunción de fondo y forma. Cualquier avance en el dominio de la competencia literaria implicará profundizar en nuevas formas de percibir y pensar la realidad y a nosotros mismos, en otras manera de disfrutar la belleza del lenguaje como herramienta magnífica. Semejante esfuerzo se traduce en nuevos esquemas cognitivos, emocionales y éticos, liberados de los prejuicios, de las condiciones estereotipadas de pensamiento que tienden a imponer los grupos sociales dominantes y que acallan la subjetividad y la autonomía y, finalmente, la posibilidad de transformar el entorno y a nosotros mismos.

\section{Habilidades emocionales}

- Manejo de los sentimientos y las emociones: El tópico más tétrico del escritor presenta una persona desequilibrada, que frecuentemente acaba destruida por sus fantasmas, el alcohol o el suicidio. Tal nefasto prototipo no puede ocultarnos cuántos seres en circunstancias límites (encarcelamientos prolongados, destierros, enfermedades, deprivaciones afectivas...) han superado su calvario a través de la 
creación de otros mundos más propicios, plagados de belleza, humor y sentido. El conocimiento sobre la naturaleza humana que aporta la experiencia literaria, el acercamiento a sus desbordamientos emocionales, a sus pozos de angustia y también a su capacidad de superación, ayuda a comprender que la angustia, la inseguridad, el miedo pero también la sensación de placer extático o incluso de omnipotencia son raptos pasajeros que pueden (y deben) ser equilibrados y dosificados y que la plasmación estética de esas emociones intensas constituye una vía sumamente productiva para lograrlo. Así lo declara N. Goldberg: "si queréis emborracharos no bebáis whisky; leed en voz alta a Shakespeare, Tennyson, Keats, Neruda, Hopkins, Millay, Whitman y dejad que vuestro cuerpo cante con ellos"15.

- Manejo de las tensiones y el estrés: La degustación y la expresión literaria aportan un placer estético, cuando se cuenta con suficientes estrategias para hacerlo con adecuada profundidad, lo cual actúa como un excepcional sedante de las tensiones internas mucho más eficaz y saludable que el que aportan las drogas anestesiantes y nocivas o los comportamientos escapistas y autodestructivos tan usuales hoy: "... entre los placeres más nobles, más humanos, está el estético. El arte calma ansiedades. El desasosiego que provoca la ansiedad y la angustia de esta época, tan competitiva y despiadada, puede quedar, al menos relativamente en suspenso, ante la gratificación emocional (bio-psíquico-cultural) que origina lo bello para quien sabe disfrutarlo [...] La creatividad (lectora o escritora) es una competencia revitalizante y reestructurante " ${ }^{\text {"16 }}$. No en vano, teóricos de la resiliencia como Desetta y Wolin ${ }^{17}$ destacan, igual que otros muchos, por cierto, el poder "curativo" de la escritura a través de la resignificación que esta permite de la propia biografía, como bien subraya la corriente de la psicoterapia narrativa. En el Project Resilience que lideran Sybil y Stephen Wolin esta función terapéutica se traslada fuera de un entorno clínico dominado por el terapeuta para concretarse en una revista, Youth Communication, que acoge los escritos de adolescentes donde estos reflexionan y reescriben experiencias propias además de aspirar a lograr cierta calidad formal que, lógicamente, implica conocer, asimilar y perfeccionar las destrezas lingüísticas y estéticas.

${ }^{15}$ Goldberg, N. (1993). El gozo de escribir. Barcelona: Libros de la liebre de marzo, p. 90.

${ }^{16}$ Reyzábal, MV. (1999). Literatura y placer: paradigma estético del lenguaje. Educare-Educere, 6, 39-52; pág. 48.

${ }^{17}$ Desetta, A. y Wolin S. (1998). Youth Communication: A model Program for Fostering Resilience through the Act of Writing. Resiliency in Action, Winter, http://projectresilience.com/framesaboutus.htm.

Voces de la Educación

ISSN en trámite

Volumen 1 Año 1

Enero - Junio 2016 
Tabla $1^{18}$

\begin{tabular}{|c|c|}
\hline $\begin{array}{l}\text { PERFIL DEL ESTUDIANTE } \\
\text { RESILIENTE }^{19}\end{array}$ & $\begin{array}{l}\text { HABILIDADES PARA LA VIDA } \\
\text { INVOLUCRADAS }\end{array}$ \\
\hline Control de emociones e impulsos & $\begin{array}{l}\text { Manejo de emociones y sentimientos } \\
\text { Solución de problemas y conflictos } \\
\text { Pensamiento crítico }\end{array}$ \\
\hline Autonomía & $\begin{array}{l}\text { Conocimiento de sí mismo } \\
\text { Pensamiento crítico } \\
\text { Toma de decisiones } \\
\text { Relaciones interpersonales }\end{array}$ \\
\hline Autoestima elevada & $\begin{array}{l}\text { Conocimiento de sí mismo } \\
\text { Relaciones interpersonales } \\
\text { Empatía }\end{array}$ \\
\hline Empatía & $\begin{array}{l}\text { Empatía } \\
\text { Comunicación efectiva }\end{array}$ \\
\hline $\begin{array}{l}\text { Capacidad de comprensión } \quad \text { y } \\
\text { análisis de las situaciones }\end{array}$ & $\begin{array}{l}\text { Pensamiento crítico } \\
\text { Solución de problemas y conflictos }\end{array}$ \\
\hline $\begin{array}{l}\text { Cierto grado de competencia } \\
\text { cognitiva }\end{array}$ & $\begin{array}{l}\text { Pensamiento crítico } \\
\text { Pensamiento creativo }\end{array}$ \\
\hline $\begin{array}{l}\text { Capacidad de atención } \quad \text { y } \\
\text { concentración }\end{array}$ & $\begin{array}{l}\text { Aunque ninguna de las destrezas psicosociales se } \\
\text { centra específicamente en estas áreas, la participación } \\
\text { de los niños y adolescentes en los talleres de }\end{array}$ \\
\hline Buen sentido del humor & $\begin{array}{l}\text { Habilidades para Vivir puede contribuir en forma } \\
\text { indirecta. Las sesiones deben ser agradables y } \\
\text { divertidas y constituyen un espacio lúdico propicio } \\
\text { para desarrollar el sentido del humor }\end{array}$ \\
\hline Sentido de propósito y de futuro & $\begin{array}{l}\text { Toma de decisiones } \\
\text { Conocimiento de sí mismo } \\
\text { Pensamiento crítico } \\
\text { Pensamiento creativo }\end{array}$ \\
\hline
\end{tabular}

4. Brindar apoyo y afecto. Las fuentes de apoyo emocional en el contexto de un taller de creación literaria son múltiples. El coordinador con su actitud facilitadora y de participación y los compañeros con su atención y crítica positiva sobre la evolución de cada participante integran una trama grupal que se potencia como soporte decisivo para vencer las inhibiciones iniciales y reforzar los progresivos pasos que se van consiguiendo en el ámbito del taller y, más aún, para incentivar que ese camino iniciado no se detenga en el marco temporal de la actividad concreta y se prolongue y traslade a la vida cotidiana de cada uno de los participantes. Las muestras escritas gestadas en las sesiones que integran el taller, plasmadas en soportes diversos (murales, revistas, blogs, presentaciones infográficas...) constituyen un acicate que sobrevive a la fugacidad del encuentro creativo concreto.

5. Establecer y comunicar expectativas elevadas. Mediante un quehacer literario adecuadamente planificado, se propone un objetivo que muchos de los participantes vivencian como inalcanzable, pero se aportan las estrategias adecuadas para comprender

\footnotetext{
${ }^{18}$ Mantilla, L. (2001). Habilidades para la vida. Una propuesta educativa para la promoción del desarrollo humano y la prevención de problemas psicosociales. Bogotá: Fe y Alegría, p. 13.

${ }^{19}$ Munist, M., Santos, H., Kotliarenco, MA., Suárez, EN., Infante, F., Grotberg, E. (1998). Manual de identificación y promoción de la resiliencia en niños y adolescentes. Santiago de Chile: Organización Panamericana de la Salud.

Voces de la Educación ISSN en trámite 
y experimentar que ello no es así. Ofrecer un espacio, tiempo y orientaciones necesarias para desarrollar exitosamente una capacidad aparentemente destinada solo a los privilegiados o "inspirados", implica animar a descubrir y a poner en marcha potencialidades que se habían reprimido o autocensurado. La retroalimentación continua (a través de los paulatinos logros en las sucesivas sesiones) de que con disciplina y un trabajo persistente y bien dirigido se puede lograr algo que se creía inalcanzable, aumenta la autoconfianza.

6. Brindar oportunidades de participación significativa: El acceso al disfrute de mensajes literarios, bien como lector bien como escritor, se acompaña de la llave para deconstruir mediante la reflexión la realidad palpable y plantear alternativas, puntos de vista, percepciones y formas de afrontarnos a nosotros mismos y al contexto que nos rodea de manera no rutinaria y renovada. Además, el que se implica en estas experiencias literarias colectivas no solo disfruta de la posibilidad de reformular su experiencia, sino de compartir y hacer una contribución activa a lo que están construyendo los que le rodean.

\section{Metodología de un taller literario orientado a promover la resiliencia}

La actitud inicial de cualquier grupo al que se le plantea un acercamiento participativo a la producción literaria (tanto en cuanto degustador como productor de textos) suele ser defensiva e incluso hostil. Lo habitual es que predomine la idea de que la producción literaria solo es posible si existe esa fuerza mágica e intangible que se denomina "inspiración"20. Una planificación esmerada (es decir, un diseño suficientemente meditado y cíclicamente revisado y adaptado a las características del grupo destinatario) y bien temporalizada de las competencias que se quieren desarrollar, de los objetivos que se pretenden lograr y de los contenidos que se desean transmitir, así como un adecuado diseño de actividades variadas y con metas bien definidas, ayudan a vencer las reticencias y los bloqueos, logro aún más completo si el conductor del taller o clase se convierte en un participante más de la escritura con la función de acompañar y dinamizar el funcionamiento del grupo.

La elección de textos de referencia que sirvan como modelo de partida constituye otro elemento fundamental. El docente o coordinador habrá de buscar escritos con dificultad variable, temática plural y ser preciso en la graduación de la complejidad formal de los mismos. El rico acervo de creaciones artísticas tanto en lengua española como en el resto de la literatura universal ofrece sugerentes posibilidades para seleccionar textos que estimulen la reflexión sobre aspectos tan diversos como la valoración de las diferencias entre los seres humanos $^{21}$, la demostración de la frecuentemente negada capacidad creadora y encauzadora vivencial de las mujeres ${ }^{22}$ o el conocimiento y aprecio de las riquezas de otras culturas diferentes a la nuestra ${ }^{23}$.

A partir de las obras seleccionadas, el coordinador de la actividad implementará con los integrantes del naciente grupo una tarea de descodificación lo más exhaustiva posible, que transmita a los lectores, más o menos neófitos, la extraordinaria riqueza que encierra incluso la composición aparentemente más simple; he aquí algunos de los infinitos campos de análisis de cualquier texto por sencillo que sea:

a) las claves temáticas y principales motivos tratados;

b) la conexión de la obra con la biografía del que la escribió y su momento histórico, así como su vigencia en el presente;

${ }^{20}$ Reyzábal, MV. (2009). La lírica: técnicas de comprensión y expresión (3ª ed.). Madrid: Arco Libros.

${ }^{21}$ Querol, JM. Y Reyzábal, MV. (2008). La mirada del otro. Madrid: La Muralla.

22 Reyzábal, MV. (2003). Mujer y literatura: la dificultad de crear mundos propios. Notas, $\mathrm{n}^{\circ}$ 15, 40-44. Reyzábal, MV. (2012). Canon literario y diferencia de género en la educación. Madrid: La Muralla.

${ }^{23}$ Reyzábal, MV. y otros (2008). El mismo azul. Aplicaciones didácticas. Ávila: Artemisa.

Voces de la Educación

Volumen 1 Año 1

ISSN en trámite

Enero - Junio 2016 
c) la riqueza sonora y rítmica que encierra y las posibilidades cuando es leída/interpretada para uno mismo o para un auditorio;

d) las características estilísticas y cómo se modificaría el conjunto si se plasmara de otra forma (cambiando el género, el tipo de protagonista, el registro léxico que emplea...);

e) los sentimientos, reflexiones o respuestas que nos suscita y la forma en que podemos plasmar todo ello (en un ensayo, un poema, un cuento, una parodia, una noticia, un collage, una canción).

La capacidad del conductor del taller para proporcionar las informaciones básicas (contenidos principalmente conceptuales e introducción en determinados procedimientos de trabajo) con el fin de llevar a cabo esa deconstrucción de la obra y para sugerir qué indagaciones complementarias podrían enriquecer el grado de comprensión de la misma (lecturas de ampliación, búsquedas bibliográficas, entrevistas con especialistas que puedan estar conectados con el tema o que hayan investigado sobre el mismo, composición de piezas que reinterpreten algún aspecto del texto...) ayudará a que aumente el gusto por el disfrute de las composiciones literarias. Ello facilitará el salto hacia la valoración de las propias creaciones, pues estas ya no se concebirán como el fruto de un acierto circunstancial, sino de un trabajo meditado y concienzudo del que sentirse satisfecho, más allá de las puntualizaciones o correcciones hechas por el coordinador, los compañeros o ellos mismos en cuanto autores que desean pulir cada vez más lo que han escrito, entendiendo que un "producto finalizado" supone un proceso repetido de corrección y reformulación y no el fogonazo inspirado de un estallido momentáneo.

La producción literaria da cabida a cualquier cuestión vinculada a las preocupaciones y anhelos de los seres humanos. Se trata, en definitiva, de una actividad transversal que permite adentrarse en cualquier materia susceptible de aprendizaje ${ }^{24}$ : desde la política a la ciencia pasando por la sociología, la psicología, la arquitectura, la pintura, la economía... o cualquier otro ámbito de conocimiento que se nos ocurra. Conviene no olvidar, como ya sugería en el apartado anterior, que mientras disfrutamos y desentrañamos o producimos textos narrativos, poéticos, ensayísticos o dramáticos, entramos en contacto con nuestro interior y a la vez nos proyectamos hacia la subjetividad de los otros para interpretarla, comprenderla o empatizar con ella.

A la vez, la tarea que se realiza en este tipo de grupos permite combinar la actividad individual con el intercambio colectivo en múltiples formas:

a) mediante el comentario de textos en grupos de discusión o de investigación;

b) a través de actividades lúdicas de producción común;

c) vía foros en los que se lean públicamente las producciones propias o las de otros (en este caso añadiendo el esfuerzo de adentrarse en descifrar la intención comunicativa del autor);

d) creando subgrupos que ejerzan la crítica constructiva de las producciones aportadas por sus integrantes;

e) estimulando la gestación de grupos autoestructurados que se encarguen de culminar una faceta especialmente gratificante para muchos escritores noveles: la publicación (en boletines, revistas impresas o en algunos de los múltiples foros que proporcionan las nuevas TIC) y difusión de sus escritos, bien como formas puramente literarias, bien como producciones mixtas que integren elementos audiovisuales o gráficos.

\footnotetext{
${ }^{24}$ Tenorio, P. y Reyzábal, MV. (1994). El aprendizaje significativo de la Literatura (2ª ed.). Madrid: La Muralla. Reyzábal, MV. y Sanz, AI. (2002). Los ejes transversales, aprendizajes para la vida. Madrid: Cisspraxis. Voces de la Educación ISSN en trámite 


\section{Conclusiones}

Como señalaba en un artículo reciente ${ }^{25}$, no existen baremos que permitan cuantificar económicamente lo que aporta la literatura a los individuos o a los pueblos; cualquier indicador numérico al respecto devendría paupérrimo reflejo del potente impacto que la creación verbal (oral u escrita) y la potencia editorial tienen sobre las personas y las economías, que tan bien conocen y manipulan desde hace siglos aquellos sectores que aspiran a concentrar poder (sea el empresarial, el religioso o el político). Las manifestaciones verbales con aspiraciones literarias ofrecen un amplísimo potencial para hacernos crecer cognitiva, emocional, social y éticamente. Son ya muchas las "pruebas" científicas que únicamente confirman lo que era evidente para muchos que ponían la pluma por encima de la espada o que exhortaban a "leer para vivir". Leer o escribir con ánimo de deleitarse o deleitar a otros no debería ser o concebirse siquiera como privilegio de unos pocos "elegidos de las musas", sino reivindicarse y autoerigirse en posibilidad de expansión de todo aquel que aspire a ser mejor persona, más consciente de sí mismo y de los mundos que le rodean, los cuales le invitan a participar en ellos e incluso a crearlos. De hecho, convendría luchar por semejante competencia como vía irrenunciable para convertirse en ser humano pleno, más allá de otras capacidades. Países muy desarrollados empiezan a invocar los saberes humanísticos (y la expresión literaria es uno de los más destacados) como básicos para avanzar en cualquier otra disciplina (sea tecnológica, científica o económica). Para lograr ser un buen lector o escribir con una cierta calidad, solo hace falta un guía, que puede coexistir en nuestro aquí y ahora o buscarse en el bien nutrido Parnaso de los ya consagrados o, -¿por qué no?- de los genios presentes no reconocidos todavía cuyas voces nos llegan a través de canales clásicos u ortodoxos (libros de papel) o no (los muros de los edificios, los espectáculos callejeros..) y de los que hace posible la tecnología digital, tales como blogs, libros electrónicos, micropoesía en redes sociales, aplicaciones informáticas creadas para ofrecer relatos que "crecen" interactivamente...

\footnotetext{
${ }^{25}$ Reyzábal, MV. (2015). ¿Tiene la poesía valor añadido? La escurridiza dimensión material de la actividad poética. Zurgai, 6, 6-11. 